\title{
Cadaveric Evidence of Complete Transection of the Lumbar Sympathetic Trunk After Extreme Lateral Transpsoas Approach to the Lumbar Spine: A Word of Caution
}

\author{
Joe Iwanaga ${ }^{1}$, Tyler Zeoli ${ }^{1}$, Tyler Scullen ${ }^{1}$, Christopher Maulucci ${ }^{1}$, R. Shane Tubbs ${ }^{2,}$ 3, 4 \\ 1. Department of Neurosurgery, Tulane University School of Medicine, New Orleans, USA 2. Neurosurgery and \\ Structural \& Cellular Biology, Tulane University School of Medicine, New Orleans, USA 3. Neurosurgery, Ochsner \\ Neuroscience Institute, Ochsner Health System, New Orleans, USA 4. Department of Anatomical Sciences, St. George's \\ University, St. George's, GRD
}

Corresponding author: Joe Iwanaga, iwanagajoeca@gmail.com

\begin{abstract}
Lateral transpsoas approaches to the lumbar spine are believed to entail less risk of injury to the lumbar sympathetic trunk and plexus than anterior approaches. However, even the lateral approach can occasionally injure the sympathetic trunk. We report a literature review and cadaveric case of complete resection of the left sympathetic trunk at L3 following lateral transpsoas approach performed by a welltrained spine surgeon. A left lateral approach to the lumbar spine for a two-level total discectomy at L3-L4 and L4-L5 was undertaken on a fresh-frozen cadaver by an experienced spinal surgeon. The procedure followed standard spinal technique under fluoroscopy guidance. The cadaver was placed in a right lateral position and an operative corridor to the lateral aspect of the psoas major muscle was developed. Blunt dissection was carried through the muscle and standard total discectomy was completed at the target levels. Following the procedure, the lumbar spine and adjacent structures were anatomically dissected. It was found that the sympathetic trunk had been completely transected at the L3 level during the surgical procedure. Other major structures such as the femoral nerve, obturator nerve, and roots of the lumbar spinal nerves had not been injured. The above case highlights the proximity of the sympathetic trunk to lateral transpsoas approaches and the possibility of injury to it. We review the literature on postoperative cases of lumbar sympathetic dysfunction (SD) following such procedures and posit that some of these are due to direct iatrogenic injury.
\end{abstract}

Review began 03/21/2021 Review ended 04/05/2021 Published 04/07/2021

\section{(c) Copyright 2021}

Iwanaga et al. This is an open access article distributed under the terms of the Creative Commons Attribution License CC-BY 4.0., which permits unrestricted use, distribution, and reproduction in any medium, provided the original author and source are credited.
Categories: Neurosurgery, Anatomy

Keywords: lumber sympathetic trunk injury, surgical training, transpsoas approach, spine surgery

\section{Introduction}

Extreme and direct lateral transpsoas approaches have grown in popularity as minimally invasive corridors for managing mid and upper lumbar spinal pathologies [1]. Ideally, the approach avoids peritoneal and retroperitoneal structures by dissecting through the muscles of the abdominal wall (internal and external obliques, transversus abdominis) and the lateral axial skeleton [1]. Deviation of the dissection plane into the retroperitoneum or peritoneum entails a risk of injury to urinary and gastrointestinal tract structures, and targeting of the more caudal vertebrae and disc spaces entails a greater risk of injury to the lumbar and lumbosacral plexuses if not accounted for during pre-operative planning [2-4]. Therefore, anatomical studies are continuing to seek ways of minimizing the risk of injury [5-8]. As with any surgery, complex minimally invasive spinal surgery necessitates strong anatomical knowledge in addition to technical capability [1]. Nevertheless, even the skilled and well-trained surgeon must be prepared for the unexpected owing to anatomical variations or unusual circumstances. We report a case of complete transection of the lumbar sympathetic trunk demonstrated by anatomical dissection following a lateral transpsoas surgical approach to the mid lumbar spine using a cadaveric specimen.

\section{Case Presentation}

As part of a surgical demonstration course, a left lateral transpsoas approach to the mid lumbar spine for a two-level total discectomy at L3-L4 and L4-L5 was undertaken on a fresh-frozen Caucasian male adult cadaver (middle-sized) by an experienced spinal surgeon (over 10 years in practice) who was a participant in the course. The procedure followed normal operative spinal technique under fluoroscopy guidance. The cadaver was placed in the right lateral position with standard adjustments to open the lateral lumbar corridor. The skin was incised per standard procedure and dissection continued down through the lateral abdominal wall to the lateral aspect of the psoas major muscle. Following fluoroscopic confirmation of position, blunt dissection was carried through the muscle and successive dilators, and self-retaining retractors were subsequently placed to visualize the target disc spaces. The L3-L4 and L4-L5 disc spaces were then subjected to annulotomy and total discectomy. 


\section{Cureus}

Following the procedure, the lumbar spine and adjacent structures were anatomically dissected via a retroperitoneal anterior approach. It was found that the sympathetic trunk had been completely transected at the L3 level during the surgical procedure (Figure 1). Other major structures such as the femoral nerve, obturator nerve, and roots of the lumbar spinal nerves had not been injured.

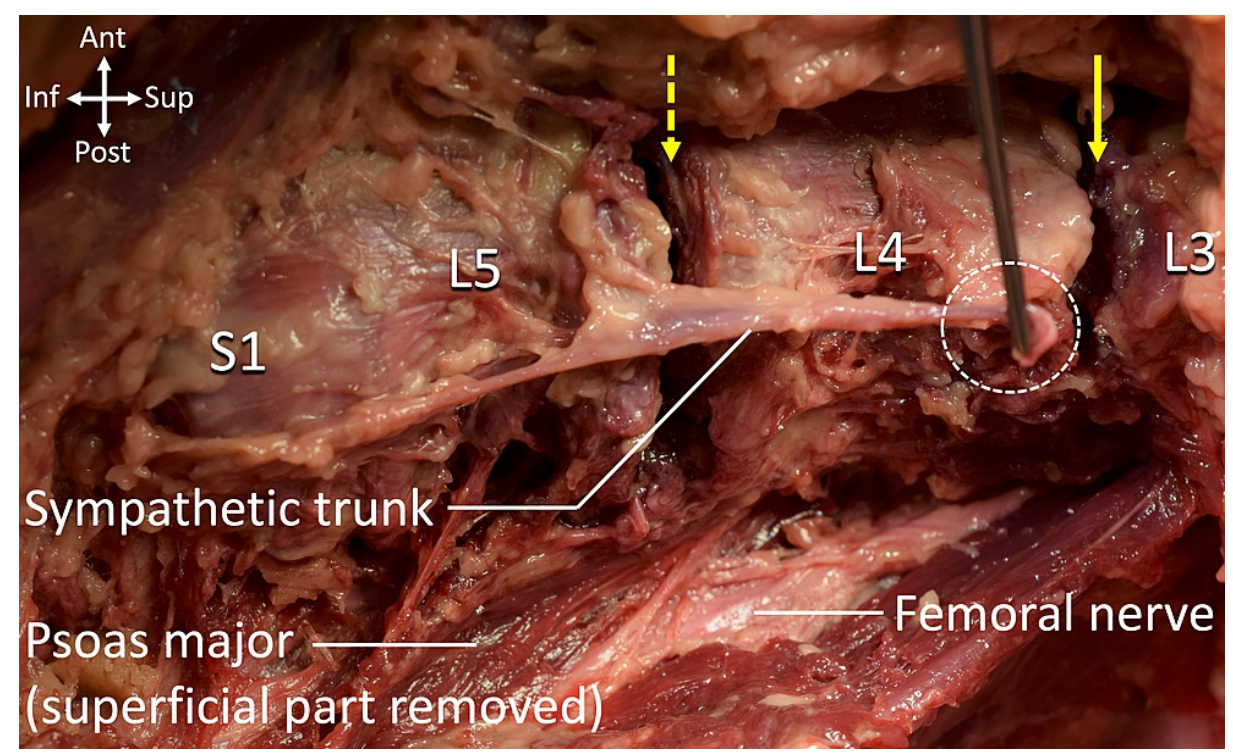

\section{FIGURE 1: Cadaveric specimen following direct lateral transpsoas approach for total discectomy of the L3-L4 (arrow) and L4-L5 (dashed arrow) intervertebral discs.}

Note: The lumbar sympathetic trunk was completely transected at the L3 level.

\section{Discussion}

The lumbar sympathetic trunk is connected to the ventral ramus of the lumbar spinal nerves via the gray and white rami communicantes and usually contains four interconnected ganglia sitting in the extraperitoneal connective tissue on the anterolateral surface of the lumbar vertebrae along the medial border of the psoas muscle found the disc spaces at L2-L3 and L3-L4 to be the levels at which the lumbar sympathetic ganglia were usually located, an area where anatomical variations are frequent [8-12].

Although injury to the sympathetic trunk is not fatal, it can carry significant morbidity secondary to deficits in a patient's quality of life $[11,12]$. The main advantage of the lateral transpsoas approach over the anterior transperitoneal, retroperitoneal, or prepsoas approaches is that there is no need to expose the great vessels, abdominal viscera, or sympathetic trunk [13]. The lateral approach also retains the benefits of minimally invasive surgery, requiring a smaller incision, less abdominal wall injury, and shorter hospital stays [13]. However, one major risk of the lateral approach, particularly in the caudal lumbar spine, is an injury to the spinal nerves as they exit via the neural foramina and course through the psoas muscle to form the lumbar plexus [14].

Lumbar sympathetic dysfunction (SD), carrying multiple potential clinical presentations such as dislocation, dysesthesia, reduced perspiration, increase in skin temperature, and swelling of the lower limb, has been reported in $4 \%$ of patients undergoing lateral transpsoas approaches at T12-L5, though this is $15 \%$ lower than the rate of injury documented during anterior approaches at the same levels [15]. Additional possible complications include retrograde ejaculation due to injury to the sympathetic plexus (well known in the urology literature), which occurs more often during dissection of the anterior longitudinal ligament in anterior approaches [16].

As mentioned, the lumbar sympathetic trunk usually runs along the medial border of the psoas $[9,10]$. This is one reason why many lateral approaches use the transpsoas corridor [1-4]. In the lower lumbar spine, anterior dissection can also injure the superior hypogastric plexus [17]. Clinically, the etiology of perioperative neuropathy can be difficult to confirm, as it is not always feasible to determine what occasioned the nerve injury (compression, traction, partial or total resection, etc.) [17]. Although we recognize that cadaveric and living tissues are very different in consistency, appearance, and physical reaction to surgical manipulation and dissection, we consider it plausible that perioperative lumbar SD has been underreported in patients undergoing minimally invasive lateral spinal procedures. Either anatomical variation of the course of the sympathetic trunk or technical issue might have caused the injury in the 
present case. This might be a good example that even well-experienced surgeons need to revisit the anatomy and basic technique so that iatrogenic injuries might be avoided.

\section{Conclusions}

We described a cadaveric report of iatrogenic lumbar sympathectomy following lateral exposure of the midlumbar spine for two-level discectomy by an experienced spine surgeon. To our knowledge, this is the first report of a cadaveric case demonstrating complete resection of the lumbar sympathetic trunk after a lateral transpsoas approach to the lumbar spine. This complication and its perioperative clinical consequences may be difficult to diagnose and avoid, even in the hands of experienced spinal surgeons. We urge spinal surgeons to further consider the lumbar sympathetic trunk and its anatomy in perioperative planning for lateral approaches.

\section{Additional Information \\ Disclosures}

Human subjects: Consent was obtained or waived by all participants in this study. Conflicts of interest: In compliance with the ICMJE uniform disclosure form, all authors declare the following: Payment/services info: All authors have declared that no financial support was received from any organization for the submitted work. Financial relationships: All authors have declared that they have no financial relationships at present or within the previous three years with any organizations that might have an interest in the submitted work. Other relationships: All authors have declared that there are no other relationships or activities that could appear to have influenced the submitted work.

\section{References}

1. Ozgur BM, Aryan HE, Pimenta L, Taylor WR: Extreme Lateral Interbody Fusion (XLIF): a novel surgical technique for anterior lumbar interbody fusion. Spine J. 2006, 6:435-443. 10.1016/j.spinee.2005.08.012

2. Rodgers WB, Gerber EJ, Patterson J: Intraoperative and early postoperative complications in extreme lateral interbody fusion: an analysis of 600 cases. Spine (Phila Pa 1976). 2011, 36:26-32. 10.1097/BRS.0b013e3181e1040a

3. Tormenti MJ, Maserati MB, Bonfield CM, Okonkwo DO, Kanter AS: Complications and radiographic correction in adult scoliosis following combined transpsoas extreme lateral interbody fusion and posterior pedicle screw instrumentation. Neurosurg Focus. 2010, 28:E7. 10.3171/2010.1.FOCUS09263

4. Isaacs RE, Hyde J, Goodrich JA, Rodgers WB, Phillips FM: A prospective, nonrandomized, multicenter evaluation of extreme lateral interbody fusion for the treatment of adult degenerative scoliosis: perioperative outcomes and complications. Spine (Phila Pa 1976). 2010, 35:S322-S330. 10.1097/BRS.0b013e3182022e04

5. Banagan K, Gelb D, Poelstra K, Ludwig S: Anatomic mapping of lumbar nerve roots during a direct lateral transpsoas approach to the spine: a cadaveric study. Spine (Phila Pa 1976). 2011, 36:E687-E691. 10.1097/BRS.0b013e3181ec5911

6. Grunert P, Drazin D, Iwanaga J, et al.: Injury to the lumbar plexus and its branches after lateral fusion procedures: a cadaver study. World Neurosurg. 2017, 105:519-525. 10.1016/j.wneu.2017.06.027

7. Iwanaga J, Yilmaz E, Tawfik T, et al.: Anatomical study of the extreme lateral transpsoas lumbar interbody fusion with application to minimizing injury to the kidney. Cureus. 2018, 10:e2123. 10.7759/cureus.2123

8. Yilmaz E, Iwanaga J, Moisi M, et al.: Risks of colon injuries in extreme lateral approaches to the lumbar spine: an anatomical study. Cureus. 2018, 10:e2122. 10.7759/cureus.2122

9. Gray's Anatomy: The Anatomical Basis of Clinical Practice 41st Edition . Standring S (ed): Elsevier Health Sciences, London; 2015.

10. Murata Y, Takahashi K, Yamagata M, Takahashi Y, Shimada Y, Moriya H: Variations in the number and position of human lumbar sympathetic ganglia and rami communicantes. Clin Anat. 2003, 16:108-113. 10.1002/ca.10069

11. Epstein NE: Review of risks and complications of Extreme Lateral Interbody Fusion (XLIF) . Surg Neurol Int. 2019, 10:237.10.25259/SNI_559_2019

12. Fujibayashi S, Otsuki B, Kimura H, Tanida S, Masamoto K, Matsuda S: Preoperative assessment of the ureter with dual-phase contrast-enhanced computed tomography for lateral lumbar interbody fusion procedures. J Orthop Sci. 2017, 22:420-424. 10.1016/j.jos.2017.01.009

13. Pawar A, Hughes A, Girardi F, Sama A, Lebl D, Cammisa F: Lateral lumbar interbody fusion. Asian Spine J. 2015, 9:978-983. 10.4184/asj.2015.9.6.978

14. Graham RB, Wong AP, Liu JC: Minimally invasive lateral transpsoas approach to the lumbar spine: pitfalls and complication avoidance. Neurosurg Clin N Am. 2014, 25:219-231. 10.1016/j.nec.2013.12.002

15. Hrabalek L, Sternbersky J, Adamus M: Risk of sympathectomy after anterior and lateral lumbar interbody fusion procedures. Biomed Pap Med Fac Univ Palacky Olomouc Czech Repub. 2015, 159:318-326. 10.5507/bp.2013.083

16. Murray G, Beckman J, Bach K, Smith DA, Dakwar E, Uribe JS: Complications and neurological deficits following minimally invasive anterior column release for adult spinal deformity: a retrospective study. Eur Spine J. 2015, 24:397-404. 10.1007/s00586-015-3894-1

17. Rahn DD, Phelan JN, Roshanravan SM, White AB, Corton MM: Anterior abdominal wall nerve and vessel anatomy: clinical implications for gynecologic surgery. Am J Obstet Gynecol. 2010, 202:234.E1-234.E5. 10.1016/j.ajog.2009.10.878 